Daimon. Revista Internacional de Filosofía, no 83, 2021 pp. 185-199

ISSN: 1130-0507 (papel) y 1989-4651 (electrónico)

http://dx.doi.org/10.6018/daimon.373451

Las obras se publican en la edición electrónica de la revista bajo una licencia Creative Commons ReconocimientoNoComercial-SinObraDerivada 3.0 España (texto legal). Se pueden copiar, usar, difundir, transmitir y exponer públicamente, siempre que: i) se cite la autoría y la fuente original de su publicación (revista, editorial y URL de la obra); ii) no se usen para fines comerciales; iii) se mencione la existencia y especificaciones de esta licencia de uso. (c) (1)(8) $(-)$

\title{
Acoger la excepción. La prudencia del juez como punto de conexión entre las ideas schmittianas y aristotélicas
}

\section{Embrace the exception. The prudence of the judge as a point of connection between Schmittian and Aristotelic ideas}

\author{
JOAQUÍN GARCÍA-HUIDOBRO* \\ DIEGO PÉREZ LASSERRE**
}

\begin{abstract}
Resumen: Este trabajo pretende justificar que, aun cuando es cierto que hay diferencias entre la filosofía aristotélica y la schmittiana, existe un punto de conexión entre ambos en lo que se refiere a la prudencia. En particular, se pretende demostrar que en la descripción que hace Schmitt de la función del juez en Ley y Juicio (1912) y en Sobre los tres modos de pensar la ciencia jurídica (1934) están presentes ideas propias de la filosofía práctica del Estagirita.

Palabras clave: Schmitt, Aristóteles, función judicial, prudencia.
\end{abstract}

\begin{abstract}
This work aims to justify that, although it is true that there are differences between Aristotelian and Schmittian philosophy, there is a point of connection between both in what refers to prudence. In particular, we intend to demonstrate that in Schmitt's description of the role of the judge in Law and Judgment (1912) and On the three types of juristic thought (1934) ideas of the practical philosophy of the Stagirite are present.
\end{abstract}

Keywords: Schmitt, Aristotle, judicial role, prudence

Diversos autores han intentado mostrar la distancia que existiría entre el pensamiento jurídico de Carl Schmitt y la idea aristotélica del derecho natural (Löwith, 1948, 32-71). Entre los contrastes más notorios entre ambos cabe señalar, primero, el hecho de que el jurista alemán considere que la visión moderna del cosmos excluye su consideración teleológica, que parece esencial a toda la filosofía práctica de Aristóteles. En segundo lugar, la categoría de la excepción, que juega un papel tan relevante en la concepción schmittiana de

Recibido: 26/04/2019. Aceptado: 26/07/2019.

* Profesor de Ética en la Universidad de los Andes, Chile. Doctor en Filosofía y en Derecho. Dirección postal: Mons. Álvaro del Portillo N²12.455, Las Condes, 7620001, Santiago, Chile. Correo: jgh@uandes.cl.

** Docente Investigador en la Facultad de Derecho y Gobierno de la Universidad San Sebastián, Valdivia, Chile. Licenciado en Derecho en la Pontificia Universidad Católica de Chile. Magister en Pensamiento Contemporáneo: Filosofía y Pensamiento Político. Actualmente cursa estudios de doctorado en la Universidad Diego Portales y la FernUniversität in Hagen (Alemania) financiados por CONICYT (CONICYT-PCHA/Doctorado Nacional/2019-21190052). Dirección postal: General Lagos 1163, Valdivia, Chile. Correo: diego.perezl@uss.cl. Los autores agradecen el apoyo de Fondecyt (proyecto n. 1190199) y del Nicola Center for Ethics \& Culture de la Universidad de Notre Dame, lo mismo que las atinadas observaciones de los revisores anónimos de este texto. 
lo político, parece inconciliable con la idea de algunos principios o al menos acciones cuya justicia o injusticia no depende del consenso social o de la voluntad del soberano, sino de la naturaleza misma (Aristóteles, 1107, 9-17). Finalmente, para Schmitt la dialéctica amigo/ enemigo está presente en toda relación política, mientras que la amistad está en la base de la política aristotélica (de hecho, se le dedican dos libros enteros en la Ética a Nicómaco). Para el pensador alemán, esa dialéctica tiene su expresión máxima en el fenómeno de la guerra, pero - más en general - en momentos de crisis en los que cae el orden normal y las propias reglas pierden su fuerza de ley. La norma, en efecto, no puede abarcar el caso en que todo, incluso ella misma, está puesto en juego. En esta posición Schmitt no está solo, porque incluso un adversario intelectural suyo, Leo Strauss, hace consideraciones semejantes en su famosa obra Natural Right and History (Strauss, 1971).

Con todo, en un trabajo publicado en 2014, Hugo Herrera hace ver que, a pesar de las diferencias señaladas, cabe notar una continuidad entre las reflexiones schmittianas y la filosofía práctica aristotélica, comprendida su concepción del derecho natural (Herrera, 2014, 205-222). En las páginas que siguen intentamos mostrar otro punto de contacto que se da a través de la noción aristotélica de prudencia y las reflexiones sobre la figura del juez que ofrece Schmitt.

Nos embarcaremos en esta travesía schmittiana-aristotélica de acuerdo al siguiente mapa de ruta: comenzaremos haciendo un breve análisis de lo expuesto por Herrera en su artículo "Aristóteles y Carl Schmitt sobre el derecho natural" (I). Luego, pasaremos a revisar las reflexiones que Schmitt hace sobre los jueces y sus funciones en Ley y juicio (1912) (II) y Sobre los tres modos de pensar la ciencia jurídica (1934) (III), para después analizar los puntos de encuentro de tales consideraciones con lo expuesto por el Estagirita sobre la prudencia (IV). Por último, sacaremos algunas conclusiones de lo expuesto (V).

\section{Aristóteles y Schmitt: el análisis de Herrera}

$\mathrm{Al}$ caracterizar el pensamiento schmittiano, sostiene Herrera que nuestra existencia, que debe enfrentarse constantemente a la tensión entre la generalidad de las normas y la singularidad de la excepción, supone ciertas condiciones que hacen posible la apertura que la caracteriza. Ellas son tres y, de modo sorprendente, cabe mostrar que pueden ser explicadas en clave aristotélica.

La primera condición de posibilidad de nuestra existencia es la diferencia entre inmanencia y trascendencia, pues sin ella no podríamos conocer, ya que permaneceríamos inmersos en la realidad inmediata, cautivos de ella. La aludida distancia impide que quedemos como fundidos con los fenómenos que conocemos, de modo que ella es la condición de toda comprensión. Por eso podemos concebir la idea de excepción, que no abarca solo la excepción política, sino toda suerte de fenómenos ante los cuales las categorías ordinarias no nos entregan una respuesta, como sucede con la muerte y con todo aquello ante lo que experimentamos inseguridad y angustia.

Esta idea de la trascendencia respecto de la realidad que nos rodea se expresa en Aristóteles de muchas maneras. De modo muy particular, cuando afirma que el alma es, en cierta medida, "todas las cosas" (Anima, III, 8) está afirmando esa, por llamarla de alguna manera, "superioridad" o trascendencia respecto de aquello que la circunda, pues significa que no queda presa de ningún objeto. Si el conocimiento es la posesión intencional de una 
forma (de la idea de una cosa, diríamos hoy), eso implica que el cognoscente está abierto al mundo, pues las formas que la realidad puede poseer de modo intelectual son infinitas.

La trascendencia tiene también importantes consecuencias políticas. En toda la Ética y la Política está presente la idea de que lo propio del hombre libre es la capacidad de abrirse a lo común. Él delibera, junto al resto de los ciudadanos, sobre las cosas que conciernen a todos. El esclavo, en cambio, pertenece al mundo de lo privado, por eso no puede ser un ciudadano.

Por último, cuando se trata de los criterios mismos de justicia, los hombres tampoco quedamos presos de la inmanencia, pues lo justo político no se agota en lo que está puesto por la voluntad humana o en los criterios que corresponden a un determinado lugar, sino que también existe lo justo por naturaleza, que tiene valor en todas partes, independientemente del hecho de que a la gente le parezca así o no (Aristóteles, 1107, 9-17). Esto tiene una gran importancia en el derecho vivo, el que se presenta en los concretos problemas o conflictos que hay que resolver, pues el caso que tiene delante un juez no es un hecho bruto, sino que posee él mismo un sentido, que es necesario descubrir.

La segunda condición de posibilidad de nuestra existencia que permite su apertura es su finitud y precariedad. Nuevamente existen aquí sorprendentes coincidencias con Aristóteles, pues, para él, un ser perfecto, es decir, que no esté afectado por la precariedad, estaría de modo necesario cerrado sobre sí mismo. La divinidad de Aristóteles no entra en contacto con los hombres, ni mucho menos puede entablar relaciones de amistad con ellos. Ella solo se conoce a sí misma, que es el único objeto adecuado para una inteligencia infinita. La finitud, en cambio, caracteriza las creaciones humanas, incluida una tan importante para la política como es la ley, que por su carácter necesariamente general no puede preverlo todo, porque la realidad es siempre más rica de lo que puede haber previsto el legislador más sabio. Por eso surge el famoso problema de la equidad (epieikeia), que trata Aristóteles en el libro V de la Ética:

"lo equitativo es justo, pero no [lo justo] según la ley, sino una corrección de lo justo legal. La causa es que toda ley es general, y hay cosas de las que no es posible expresarse correctamente en forma general. Entonces, en los casos en que es necesario expresarse en términos generales, pero no es posible hacerlo correctamente, la ley considera lo que se da las más de las veces, sin ignorar el error.

Y no es [por eso] menos correcta, pues el error no está en la ley ni en el legislador, sino en la naturaleza de la cosa, pues tal es, sencillamente, la materia de las [cuestiones] concernientes a la acción. Por tanto, cada vez que la ley habla en términos generales, pero de hecho se da, en lo que atañe a ella, algo [que está] al margen de lo general, entonces es acertado, allí donde el legislador no atendió a algo y cometió un error por hablar en sentido absoluto, corregir la omisión; eso diría el propio legislador de estar ahí presente; y si hubiese previsto [el caso particular en cuestión], [lo] habría incluido en la ley. Por eso [lo equitativo] es justo, y mejor que cierta forma de lo justo, pero no mejor que lo justo en sentido absoluto, sí [es] mejor que el error causado por [el hecho de expresarse] en sentido absoluto. Y esa es la naturaleza de lo equitativo: ser corrección de la ley en tanto esta incurre en omisiones a causa de su índole general" (EN V 10, 1137b11-27). 
No se trata aquí, propiamente, de una falla de la ley. Simplemente sucede que, por su propia naturaleza finita, ella no puede ponerse en todos los casos y por eso dispone respecto de lo que sucede en general, es decir, la mayoría de las veces. En efecto, una ley que pretendiera hacerlo, es decir, que buscara eludir la condición finita de lo humano, no sería una buena ley, porque carecería de la simplicidad que permite que ella sea conocida con facilidad y prontitud.

La cuestión de la equidad conecta las dos formas de justicia política que reconocía Aristóteles, la natural y la legal, pues ante casos semejantes la norma positiva no solo se queda corta, sino que empieza a ser injusta si se aplica en su literalidad, lo que significa que se está negando a sí misma, pues abdicaría de su razón de ser, ya que sería un obstáculo para ordenar las conductas humanas de manera justa. La norma misma queda, para decirlo en terminología schmittiana, puesta en juego, cuestionada. La diferencia entre Aristóteles y Schmitt reside en que, para el segundo, el caso excepcional se resuelve prescindiendo de la norma, mientras que, para Aristóteles, al aplicar su sentido por encima de su letra, se la está realizando más plenamente que en su mera aplicación literal. Esto es posible porque el juez no está preso de la inmediatez, sino que puede abrirse a una forma más noble de justicia. Pero, si se observa con atención, la diferencia aquí es solo de palabras, porque mientras el jurista alemán, atendidas las categorías mentales de su público, está empleando la noción moderna de norma, que es estrecha, mientras que Aristóteles la comprende en sentido clásico y mucho más amplio. Que están diciendo lo mismo lo revela una afirmación que Schmitt hace en otra de sus obras, donde habla con más libertad: "la regla vive en absoluto solo desde la excepción" (Schmitt, 2015, 21).

La tercera condición de posibilidad de nuestra existencia, y que apunta a su apertura, está dada por el carácter práctico de nuestro ser. Que los hombres seamos prácticos significa que siempre estamos en búsqueda de sentido. Aquí entra el tema de la finalidad, que Schmitt reconocía como una dimensión que estaba ausente en el pensamiento moderno. Pero él no lo introduce desde afuera, en virtud de consideraciones metafísicas, sino como una exigencia que hace posible nuestra actividad en el mundo. La búsqueda de sentido no es una tarea inútil, que está de antemano condenada al fracaso, pues el caso con el que se está confrontado tiene un sentido originario, que la norma ilumina, pero no agota, como se veía recién en el ejemplo de la equidad. Así, lo particular-excepcional también está vinculado a lo universal, pero no a la universalidad de la norma positiva, sino a esa otra justicia cuya validez es superior no por ser abstracta, sino por fundarse en la naturaleza.

Este breve análisis (y complementación) de lo dicho por Herrera nos da el impulso inicial para pasar a revisar el pensamiento jurídico de Schmitt. Esto porque, como bien explicaremos en el siguiente apartado, la crítica al positivismo jurídico y la descripción de la labor judicial que realiza el jurista alemán van de la mano con sus reflexiones sobre la importancia de la excepción. En palabras sencillas, el pensamiento jurídico, político y existencial de Schmitt toma como base la misma idea que subyace a la filosofía práctica aristotélica, a saber, que la realidad es inconmensurable, por lo que no corresponde limitarla a través de categorías cientificistas creadas por el ser humano.

\section{La inconmensurabilidad del fenómeno jurídico: el juez de Schmitt}

En Ley y juicio (1912), uno de sus primeros trabajos académicos, Schmitt ataca el positivismo jurídico imperante en aquella época. La idea detrás de esta crítica es la siguiente: 
el positivismo busca explicar una realidad incalculable o inconmensurable a través de categorías jurídicas artificiales y limitadas. Esto genera que, a través de la imposición de estas categorías a la realidad, se haga violencia a la alteridad y, a su vez, esta resulte clausurada. En palabras sencillas, el positivismo jurídico crea categorías y luego explica todo el fenómeno jurídico a partir de las mismas, de manera tal que se genera una identificación entre aquello creado por el hombre y la alteridad que se busca explicar. En lo que sigue, profundizaremos en esta crítica.

En las primeras páginas de este texto, Schmitt asevera que no debe buscarse una respuesta absoluta e intemporal a la cuestión de la rectitud de una decisión, que se deduzca de una abstracción, de una idea de corrección de la decisión judicial (Cf. Schmitt, 2012a, 14). Es decir, Schmitt comienza criticando la premisa sobre la cual se funda el positivismo jurídico, a saber, que el derecho, para ser ciencia, ha de deshacerse de la injerencia de la subjetividad humana para lograr así una objetividad (o pureza) prácticamente matemática. El jurista alemán arguye que el ideario kelseniano es un tanto ególatra, toda vez que asume que es posible explicar la totalidad de la realidad a la que se enfrenta el derecho a partir de leyes. En palabras de Schmitt,

"solo una mínima parte de los supuestos que se le ofrecen al juez para dictar sentencia pueden ser resueltos acudiendo al simple y claro contenido de la ley. Sería impensable que se pudiera resumir la regulación exhaustiva de la realidad multiforme de la vida en unos pocos artículos, de los cuales simplemente procediera la interpretación de cada caso concreto" (Schmitt, 2012a, 22).

Puesto de otro modo, el jurista alemán dirige su ataque a quienes conciben al derecho como mera tecnología, al juez como una máquina de subsunción y a la decisión judicial como el resultado de una operación aritmética.

Las críticas schmittianas recién vistas permiten elucidar la idea sobre la que se construye el pensamiento jurídico del autor, a saber, que la realidad jurídica es dinámica, por lo que una teoría o dogmática jurídica, por completa que esta sea, no basta para tener una praxis jurídica adecuada a las necesidades de una comunidad (Schmitt, 2012a, 5). Una realidad en constante cambio requiere que las decisiones judiciales que se apliquen a la misma tengan la maleabilidad suficiente como para renovarse de acuerdo con las singularidades del caso particular, para así lograr justicia respecto al caso concreto. La pregunta que surge, entonces, es la siguiente: ¿Cuál es el elemento que, dentro del ordenamiento jurídico, proporciona la flexibilidad para hacerse cargo del dinamismo del fenómeno jurídico? ¿Es acaso la ley? La respuesta es negativa, toda vez que, si bien la existencia de las normas jurídicas es necesaria para proveer una cierta seguridad jurídica a la sociedad (Schmitt, 2012a, 90), estas reglas son generales y abstractas, y, por lo tanto, se elevan por encima de los casos concretos a los que han de ser aplicadas (Schmitt, 2012b, 267). Es decir, las leyes no son capaces de hacerse cargo de los cambios que experimenta la realidad concreta justamente porque son formuladas de manera tal que estas logran abarcar un sinnúmero de casos particulares, sin importar cuán diversos y singulares sean estos (y está muy bien que sea asî). En las normas jurídicas, de hecho, encontramos lo contrario a la mutabilidad: la estabilidad. En palabras de Derrida, "el derecho es el elemento del cálculo y es justo que haya derecho" (Derrida, 1992, 142). 
Entonces, la sola ley no es suficiente para enfrentarse a la realidad concreta a la que esta ha de aplicarse. Los textos normativos no bastan, toda vez "que una ley no puede aplicarse, manipularse o ejecutarse a sí misma; no puede ni interpretarse, ni definirse, ni sancionarse, no puede tampoco por sí sola - si no deja de ser una norma - nombrar o designar a las personas concretas que deben interpretar o manejar la ley" (Schmitt, 2012b, 259, 260). Puesto de otro modo, los textos legales tienen por objeto ser aplicados a casos concretos, por lo que no pueden mantenerse eternamente en esta esfera de generalidad y abstracción. La pregunta, entonces, y como bien la formula Derrida, es la siguiente:

“Cómo conjugar el acto de justicia que debe referirse siempre a una singularidad, individuos, grupos, existencias irremplazables, el otro o yo como el otro, en una situación única, con la regla, la norma, el valor o el imperativo de justicia que tienen necesariamente una forma general, incluso si esta generalidad prescribe una aplicación cada vez singular? Si me conformo con aplicar una regla justa sin espíritu de justicia y sin inventar cada vez, en cierta manera, la regla y el ejemplo, actuaría quizás al amparo del derecho, con arreglo al derecho objetivo, pero no sería justo" (Derrida, 1992, 142, 143).

Es decir, la cuestión es cómo mediar entre dos polos: uno concreto y particular (el caso), y otro abstracto y general (la ley). Tal es, según Rasch, la interrogante que guía a Schmitt en Ley y juicio (Rasch, 2004, 98).

La respuesta de Schmitt es la siguiente: quien está encargado de generar el paso de la teoría a la praxis jurídica, de resolver la tensión entre el polo abstracto y el concreto, es precisamente el juez, que para tales efectos cuenta con una herramienta: la decisión judicial. En ese sentido, Schmitt va en contra de la posición positivista radical según la cual el juez es un mero autómata, un ente encargado de procesar los casos concretos y subsumirlos bajo las descripciones normativas. En palabras del jurista alemán, "no es posible degradar al juez a ser la «boca que pronuncia las palabras de la ley», aunque fuera en el sentido de «sometimiento a la ley»" (Schmitt, 2012a, 123). Es decir, la actividad del juez es bastante más compleja que la de una máquina procesadora de datos, toda vez que debe atenerse al texto general y abstracto, pero al mismo tiempo ha de hacer justicia a las singularidades del caso concreto.

La pregunta, entonces, es, ¿cómo logra este equilibrio? Schmitt responde señalando que, para asegurar una relativa certeza jurídica, es necesario que el juez se atenga al derecho vigente, pero que, con el fin de logar la justicia para el caso particular, debe renovar su sentido y alcance a la luz de las singularidades del caso concreto (Schmitt, 2012a, 120-124). Es decir, el juez se ubica en medio de dos polos, la ley y el caso, y debe resolver la tensión apoyándose en el primero (abstracto), pero teniendo siempre a la vista la concreción del caso particular. Kaufmann, quien tiene un pensamiento bastante cercano al de Schmitt, lo explica de la siguiente manera:

“cuando el derecho «se aplica», se realiza, sucede siempre una mediación de dos mundos: el mundo de la realidad cotidiana con sus circunstancias de vida jurídicamente relevantes y el mundo del derecho con sus normas que contiene un deber ser. 
A través de la realización del derecho el deber ser y el ser se ponen en contacto; sí, derecho es la correspondencia entre deber ser y ser" (Kaufmann, 2002, 224).

En síntesis, la función judicial es en cierto sentido creadora, ya que debe reinventar la norma positiva a luz de las particularidades del caso concreto. Debe mediar la dimensión del deber ser normativo que busca la estabilidad en el derecho, con el ser, la realidad práctica, la cual exige justicia ${ }^{1}$.

\section{Lo normal y lo anormal en el derecho: la importancia de la excepción}

En 1934, Schmitt publica un libro que lleva por título Sobre los tres modos de pensar la ciencia jurídica. Dentro de los muchos temas allí tratados se encuentra el de la relación entre el derecho y las situaciones "normales" y "anormales". Este análisis resulta clave para comprender lo que el jurista alemán decía en 1912, toda vez que pone sobre la mesa un concepto fundamental en la filosofía schmittiana, a saber, la excepción.

$\mathrm{Al}$ referirse al normativismo, pensamiento que identifica el derecho con los textos positivos, Schmitt señala que, dada la regularidad y previsibilidad en que esta se desenvuelve, es posible que ciertos aspectos de la vida humana, como lo son las relaciones contables del comercio, sean reguladas por medio de "una sencilla función de reglas generales predeterminadas" (Schmitt, 2012b, 262). Sin embargo, continúa señalando,

"hay otros ámbitos de la existencia humana para los que la extensión de ese funcionalismo regular destruiría precisamente la sustancia jurídica específica del orden concreto. Estos últimos son los ámbitos de la vida que han sido configurados, no del modo técnico-planificado para el tráfico, sino de modo institucional. Éstos tienen en sí mismos la noción de lo que es normal, de lo que es un tipo normal y una situación normal, y su concepto de normalidad no se agota, como es el caso de una sociedad de tráfico tecnificada, en la función calculable de una regulación normal. Tienen una sustancia jurídica propia, que, desde luego, conoce también reglas generales y cierta regularidad, pero sólo como expresión de esa sustancia, sólo como procedentes del propio orden interno concreto, el cual no es la suma de aquellas reglas y funciones" (Schmitt, 2012b, 263).

En esta extensa cita, Schmitt da a entender que el derecho, a través de normas jurídicas, regula, de manera abstracta y general, situaciones normales (es decir, previsibles y calculables). Sin perjuicio de lo anterior, el derecho es de aquellos fenómenos que han de confrontarse a la realidad concreta de los seres humanos; esto implica que, al momento de su aplicación, éste se encontrará no con un contexto uniforme y estable, sino con una realidad una tanto caótica, donde la normalidad es a veces la regla, pero donde la anormalidad emerge constantemente para romper el esquema normativamente regulado (Betti, 2015, 26). En otras

1 Cabe tener en cuenta que Schmitt tiene claro que su solución da lugar a una cierta laxitud en el derecho. Es por eso que señala que con su fórmula "no se pretende obtener la seguridad propia de una tabla de logaritmos o de un mapa de carreteras que frecuentemente se citan como ideal". (Herrero, 2012, p. 156). 
palabras, la excepción irrumpe inevitablemente en la realidad jurídica, lo que pone en jaque a la norma positiva, que esta está preparada para la normalidad. ¿Qué hacer, entonces, con la excepción no anticipada por la norma? Una solución a esta problemática sería legislar constantemente para así regular la excepción. Es decir, transformar la situación "anormal" en "normal". Sin embargo, esta respuesta se encuentra con al menos dos dificultades: primera, la excepción aparece y desaparece con una rapidez que el proceso legislativo no puede igualar, por lo que es probable que una vez que la ley que regula la situación anormal entre en vigencia, la situación excepcional ya haya desaparecido. Segunda, considerar que es necesaria una nueva norma positiva para regular lo excepcional produciría que las leyes que regulan las situaciones normales pierdan su fuerza rápidamente. En otras palabras, la excepción produciría la ineficacia de la regulación vigente.

Una respuesta bastante más satisfactoria la encontramos precisamente en la propuesta schmittiana de Ley y juicio. En efecto, si leemos estos dos textos de manera complementaria, es posible inferir que lo que debe hacer el juez al encontrarse en medio de la tensión del texto general - que es abstracto y regula situaciones "normales" - , y el caso particular, que presenta un carácter excepcional, donde emerge lo "anormal", es justamente renovar el sentido y alcance del texto legal a la luz del caso excepcional. La norma positiva ha de hacer suya la excepción, reinventarse en función de la nueva situación que requiere de solución. De esta manera, no se produciría una hipertrofia legislativa, ni tampoco una pérdida de eficacia de la regulación vigente ${ }^{2}$. Es decir, y como bien adelantamos respecto al pensamiento de Aristóteles en el primer apartado de este trabajo, la finitud de los textos normativos, su incapacidad para reglar todos y cada una de los casos a los que se ven enfrentados, los hace incapaces de hacerse cargo, por sí mismos, de los casos excepcionales. Quien está llamado, entonces, a dar solución a esta problemática es el juez. A través de la virtud de la prudencia, debe resolver la tensión - buscar el justo medio - entre el polo abstracto (la ley) y el polo particular (el caso concreto) ${ }^{3}$. En unas pocas palabras, el juez, mediante la decisión judicial, resuelve la tensión entre la regulación "normal" que hace el polo abstracto, y la "anormalidad" que surge del polo concreto.

El análisis que Schmitt hace en el texto que venimos comentando, entonces, es una profundización de su crítica a la idea de que el derecho, y más específicamente la función judicial, es mera tecnología. Esto nos permite entender el hecho de que Schmitt critique la absolutización de la racionalidad técnica, propia de la época actual, pues dicha racionalidad se cierra radicalmente a la excepción, que en su mundo resulta incomprensible o, al menos, constituye una falla que es necesario evitar o corregir, ya que ella solo funciona con criterios generales y no está pensada para hacerse cargo de la singularidad.

En la misma línea que Schmitt, unos años después, en Verdad y Método, Gadamer dará una explicación muy adecuada acerca de la diferencia que se da entre la racionalidad práctica y la técnica a propósito precisamente de la excepción. En el caso de las técnicas, sucede a veces que, a causa de la singularidad de la materia que es objeto del trabajo que se realiza,

2 Hay que tener en consideración, empero, que hay ciertas situaciones cuya anormalidad justifica una nueva regulación. Un ejemplo contemporáneo sería la regulación de la propiedad intelectual. Esta se justifica debido a que el objeto sobre el que recae este derecho no responde a la misma lógica que el dominio sobre las cosas corporales que existen en la realidad no-tecnológica.

3 Profundizaremos en la importancia de la prudencia judicial en el siguiente apartado. 
en una situación determinada no resulte posible seguir los criterios preestablecidos por las reglas de la disciplina para resolver un problema. Así, en 1970, los astronautas del Apolo 13 que estaban en el espacio no podían aspirar a una solución propia de un manual cuando su nave sufrió un accidente, porque ellos solo estaban en condiciones de utilizar los materiales que tenían en su cápsula espacial, que se hallaba a miles de kilómetros de distancia del lugar donde se encontraban los materiales más adecuados. Los ingenieros que estaban en tierra tuvieron que idear una forma de reparar los desperfectos que afectaban a la nave contando únicamente con los elementos que estaban disponibles en la cápsula. Naturalmente, una solución así, de emergencia, supone, en buena medida, una pérdida respecto del proyecto original. Se trata de una deficiencia que el técnico, en este caso los astronautas, tratará de remediar de la mejor manera posible, pero que necesariamente será menos perfecta que la solución que se habría encontrado en los talleres de la NASA, donde se podían seguir los protocolos preestablecidos. No sucede lo mismo en el caso de la praxis, donde el cambio respecto del plan original no necesariamente implica una pérdida de calidad de la solucion elegida. Bien puede ocurrir que un político, atendidos los cambios que derivan de una situación internacional completamente imprevista - como una guerra en los países vecinos - , no esté en condiciones de llevar a cabo unas medidas anunciadas en su programa de gobierno y deba reemplazarlas por otras, para evitar ciertos males o aprovechar una determinada oportunidad. Pero el hecho de que haya alterado su planificación original no lo transforma en un peor político ni hace perder calidad a su decisión, sino que probablemente sea todo lo contrario.

En síntesis, en la racionalidad técnica, la excepción constituye un inconveniente y está relacionada con la deficiencia. En la racionalidad práctica, en cambio, ella permite incluso apuntar a una forma superior de justicia.

\section{El valor de lo particular: entre Aristóteles y Schmitt}

Lo dicho por Schmitt tiene que ver con una importante enseñanza aristotélica, a saber, que la acción concreta presenta un contenido de verdad superior a las afirmaciones generales de la ética. En efecto, "cuando se trata de acciones, los principios universales tienen una aplicación más amplia, pero los particulares son más verdaderos, porque las acciones se refieren a lo particular y es con esto con lo que hay que estar de acuerdo" (En II 6, 1107a2835). Esto, naturalmente, no sucede en el caso de las ciencias especulativas ni incluso en las técnicas, donde lo relevante es el saber de carácter general. Por eso dice Aristóteles que, en este campo, quien comete un error adrede es mejor técnico que aquel que incurre en él de manera involuntaria (En VI 5, 1140b22-23 en relación con Met. IX 2, $1046 b 4$ ss.), porque lo importante es el saber general y no su aplicación concreta. Esto sería impensable, por ejemplo, en el caso de la justicia. Quien comete una injusticia queriendo en ningún caso podrá ser considerado justo.

Con lo anterior el Estagirita se refiriendo a que hay ciertas verdades (que Aristóteles llama prácticas) que no pretenden obtener una seguridad matemática, una certeza que mantiene su valor sin importar cuán radicalmente diferentes sean los casos particulares a los que esta se enfrente. Es decir, por medio de las verdades prácticas no se pretende obtener un conocimiento universal y abstracto cuya certidumbre sea independiente de las particularida- 
des de los casos concretos. Por el contrario, estas buscan determinar lo correcto tomando en consideración justamente el contexto específico al que el agente práctico se ve enfrentado. Ahora bien, el concepto de verdad práctica se encuentra íntimamente ligado con el análisis que Estagirita hace de la técnica (technē) y la prudencia (phronēsis). Como bien señala Vigo, la conexión entre las virtudes intelectuales prácticas de la prudencia y la técnica con el concepto de verdad práctica

\begin{abstract}
"viene dada por el hecho de que, cada una en su ámbito propio de referencia, tanto la técnica como la prudencia son disposiciones habituales que permiten a quien las posee determinar, en cada contexto de decisión y acción, los caminos y medios más adecuados para alcanzar los fines deseados, ya sean los fines de una determinada actividad productiva particular, o bien los fines más abarcadores que forman parte del diseño general de una vida buena para el hombre" (Vigo, 2007, 211).
\end{abstract}

Es decir, la prudencia y la técnica son virtudes que permiten al agente práctico determinar la correcta línea de acción a seguir a la hora de enfrentarse a numerosos y desemejantes sucesos de la vida cotidiana. La verdad práctica, por su parte, busca determinar qué es lo correcto de acuerdo con el singular contexto de una situación concreta. En ese sentido, la prudencia, virtud en la que nos centramos en el presente trabajo, se puede entender como una virtud que facilita al ser humano el descubrir la verdad práctica.

La prudencia, entonces, es la virtud encargada de proporcionar a los seres humanos la línea de acción a seguir frente a los casos particular que surgen en la siempre cambiante vida cotidiana. En palabras de Vigo:

"por lo tanto, como disposición habitual de la facultad intelectiva práctica, la prudencia pone a su poseedor en posición de producir en cada contexto particular de acción siempre aquellas acciones que, por responder a deseos rectos y ser resultado de una adecuada elección de los fines, configuran casos de realización de la verdad práctica y contribuyen, como tales, al logro de una vida buena para el agente" (Vigo, 2007, 213).

Lo anterior no significa, empero, que entonces la determinación de lo correcto desde el punto de vista práctico se realiza de manera contingente. Si bien el concepto guía de la prudencia, la verdad práctica, toma como base la idea de que no es posible determinar la acción correcta a seguir a priori, esto no importa que en ella no haya referencia a normatividad alguna. Muy por el contrario, el análisis que hace el hombre prudente a la hora de decidir el curso de acción a seguir es justamente preguntarse qué es lo universalmente correcto a la luz de las particularidades a las que se ve enfrentado. Es decir, comienza de la contingencia propia de la realidad concreta y luego reflexivamente asciende hacia una universalidad que se asume común para todos los seres humanos.

Atendido el hecho de que la verdad se da primordialmente en el caso concreto, se trata no simplemente de conocer una serie de principios generales, sino de aprender a realizar los actos de manera excelente, lo que solo se puede aprender a través del ejercicio. Por eso dice Aristóteles que aprendemos las técnicas y las virtudes - en este caso la justicia- 
"haciendo lo mismo que se debe hacer después de haberlas aprendido; por ejemplo, se llega a ser constructor de casas construyendo casas, y citaristas tocando la cítara. De este modo, pues, también llegamos a ser justos realizando actos justos, moderados realizando actos de moderación, y valientes realizando actos de valentía" (En II 1, 1103a32-1103b2

Esto significa que, sin la adecuada experiencia, no resulta posible acertar de modo permanente en materias morales, mientras que ella permite ver correctamente la situación y resolverla de modo adecuado (En VI 11, 1143b13; VI 7, 1141b16-17). La capacidad de distinguir la excepcionalidad del caso que se tiene delante, el poder comprenderlo adecuadamente en su singularidad, es la gnome, que permite discernir lo equitativo (En VI 11 1143a19-24).

La lógica detrás de filosofía práctica del Estagirita se asemeja bastante a aquella utilizada por Schmitt en los textos revisados en los apartados anteriores (aun cuando el análisis del jurista se refiere específicamente al caso del derecho). Lo excepcional siempre emergerá para romper con los esquemas predispuestos por el derecho, por lo que es imposible proporcionarles a los jueces encargados de fallar estos casos excepcionales las soluciones correctas antes de que estos ocurran (cuestión que, además, generaría magnas injusticias). El problema es, sin embargo, que, a diferencia de otras profesiones, como la del filósofo (aun cuando es dudoso afirmar que la filosofía es una profesión), el juez no puede reflexionar eternamente. Él debe decidir (y con cierta premura). Pero ¿cómo puede el juez saber si su decisión respecto a la situación excepcional es correcta?

La solución de Schmitt a esta problemática es sorprendentemente aristotélica. En efecto, el jurista alemán señala que

"no debe buscarse una respuesta absoluta e intemporal a la cuestión de la rectitud de una decisión, que, por ejemplo, se deduzca de la «idea» de la decisión judicial; esto, además no tendría tampoco ningún valor práctico. El método de la aplicación del derecho debe descubrir la idea rectora de la praxis actual, y utilizarla de manera que sirva a modo de una suerte de autorreflexión sobre sus fines y medio" (Schmitt, 2012a, 135).

Es decir, afirma que el derecho es una actividad práctica, por lo que no se ha de buscar la solución al problema de la corrección de las sentencias en cuestiones de tipo teórico. Para determinar si acaso su decisión es recta, nos dice Schmitt, al fallar sobre un caso excepcional el juez ha de realizar un ejercicio hipotético y preguntarse si acaso la solución que el pretende dar a aquel asunto sería considerada correcta por otros jueces (Schmitt, 2012a, 99 y ss.). Puesto de otro modo, asevera que el juez ha de comenzar su análisis de las particularidades del caso para luego descubrir, por medio de la reflexión, una normatividad respecto al caso particular. En palabras sencillas, para considerar que su juicio es recto, el juez debe llegar a la conclusión de que cualquier otro hombre justo fallaría del mismo modo.

Creemos que lo anterior se asemeja bastante al pensamiento aristotélico, toda vez que este último asevera, en clara sintonía con Schmitt (aunque la relación es más bien a la inversa), que el descubrimiento del sentido que nace en el caso, particularmente en el caso excepcional, no es una tarea que se lleve a cabo por la aplicación mecánica de una serie de 
reglas, sino que depende de una serie de condiciones del propio sujeto. Vimos, en efecto, que el hombre es un ser práctico, pero en materias prácticas el conocimiento de la verdad, a diferencia de lo que puede suceder en la geometría o en cualquier otra materia especulativa, depende de manera muy radical de las condiciones del propio sujeto, es decir, de la forma en que ha configurado su carácter. Por eso dice en la Ética que "el virtuoso juzga bien de todas las cosas" (Ética a Nicómaco III 3, 1113a28-29). Solo el justo resuelve adecuadamente los problemas de justicia, o el templado decide acertadamente en relación con los placeres. Asimismo, un cobarde jamás sabrá qué peligros debe enfrentar, o un perezoso cuántas horas debe dedicar al trabajo. En materias prácticas, las cosas no aparecen de la misma manera para todos, sino que son "como se le aparecen al virtuoso". Solo él es capaz de decidir adecuadamente cuando estamos en presencia de lo inusitado, de lo que no está previsto en la norma, que por definición dispone para lo habitual. Lo dicho se relaciona con la original idea aristotélica de que existe una verdad de carácter práctico, que no consiste en la adecuación entre el juicio de la inteligencia con una cosa que está en el mundo exterior, sino que es interior al sujeto mismo; ella consiste en la concordancia entre el apetito recto y la razón verdadera (En VI 2,1139a21-31). Cuando se da ese ajuste, las acciones que nacen de allí son buenas. Atendido el hecho de que la razón juzga sobre circunstancias que son muy variadas, Aristóteles enseña que en esta materia debemos proceder de modo esquemático, atendiendo a lo que sucede de modo ordinario, y nunca podemos pedir en este campo una exactitud como la que encontramos en las matemáticas (En I 3, 1094b17-27).

Es decir, tanto Aristóteles como Schmitt señalan que la solución para el caso excepcional no ha de buscarse en una idea abstracta y preconcebida de justicia. Muy por el contrario, la justicia ha de tener en consideración las particularidades del caso, por lo que es imperativo que la reflexión sobre la misma comience desde, y esté orientada hacia, la excepcionalidad del caso. En ese sentido, la personalidad del juez es insustituible. Ninguna máquina, sin importar cuán avanzada esta sea, puede hacerse cargo de la excepción. El juez, en tanto agente práctico, es el único que puede articular lo singular y contingente de la vida concreta, y la universalidad que todo concepto de "corrección” asume como básica. En palabras de Vigo,

"la tensión entre individuación y universalidad que se presenta en el ámbito de despliegue propio de la racionalidad práctica se advierte claramente, cuando se atiende a un hecho elemental, pero a menudo pasado, sin más, por alto: mientras el aspecto de autorreferencialidad pone de relieve el vínculo indisoluble que la racionalidad práctica mantiene con la indelegable individualidad del agente de praxis, el aspecto de vinculación con la dimensión de la normatividad apunta, inversamente, hacia una esfera de universalidad que trasciende al propio agente, precisamente, en lo que tiene de individuo" (Vigo, 2007, 199).

Sin perjuicio de lo anterior, hay que tener presente que Schmitt no es Aristóteles. Es decir, que si bien hay puntos de conexión entre ambos autores, también hay diferencias que no pueden ser obviadas. Una de las más evidentes (y atingentes al asunto que venimos comentando) es el contexto político en el que están pensando a la hora de tematizar la función judicial. Mientras que Aristóteles ubica al juez en la polis griega, donde la justicia depende más de las cualidades personales de los jueces en tanto concretamente considera- 
dos, Schmitt está pensando en los magistrados no como individuos concretos, sino en tanto integrantes de la institucionalidad propia del Estado moderno. Puesto de otro modo, mientras que Aristóteles se preocupa de las virtudes de los jueces como condición de posibilidad de la justicia para el caso concreto, Schmitt está pensando en el modo de justificar la corrección de las decisiones judiciales a la luz de la justicia considerada como función del Estado. Esto último, por lo demás inevitable dada la época en la que Schmitt escribe, lo lleva a alejarse del Estagirita y acercarse, de hecho, a la filosofía de Kant. En efecto, la necesidad de encontrar una validación de las decisiones judiciales en el contexto de la institucionalidad moderna dirigen al jurista alemán, como bien señalan Rasch (2004) y Herrerro (2012)4 ${ }^{4}$, directamente a la tercera crítica kantiana. Ahora bien, aun cuando una afirmación como la recién hecha justifica un extenso trabajo dedicado exclusivamente a elucidar en qué sentido específico habría una relación entre el pensamiento de Schmitt y la Crítica de la Facultad de Juzgar de Kant, nos referiremos brevísimamente a este problema.

Para justificar la corrección de una decisión judicial en el contexto del Estado moderno, como bien ya indicamos, Schmitt apela a la intersubjetividad judicial. Es decir, afirma que una decisión es correcta siempre y cuando, luego de realizar un ejercicio hipotético, el juez llegue a la convicción de que otro juez enfrentando al mismo caso hubiese fallado de igual manera. Por lo tanto, para el jurista alemán la corrección de una decisión judicial no equivale a una adecuada subsunción de los casos particulares bajo las generalizaciones contenidas en los textos legales. El juez no ha de comenzar por las abstracciones descritas por la ley para luego "aterrizarlas" en la realidad concreta como ocurre en el juicio determinante kantiano 5 . Muy por el contrario, él ha de emprender la tarea de aplicar el derecho partiendo por las particularidades del caso concreto, para luego elevarse, por medio del ejercicio hipotético antes descrito, a una instancia abstracta de legitimación intersubjetiva. Es decir, debe proceder al modo del juicio reflexionante descrito por Kant en su Crítica de la Facultad de Juzgar, donde lo que se presenta ante nuestro conocimiento es lo particular, mientras que lo universal (el concepto) es lo que se ha de encontrar (Kant, 1992, 90). En ese sentido, aunque claramente este punto requeriría una investigación autónoma para que el argumento tome forma, al pensar al juez no en tanto individuo concreto, sino que como formando parte de un entramado sistemático y ordenado que desde la modernidad conocemos como función judicial, Schmitt se acerca bastante al análisis que Kant hace sobre la capacidad de juzgar y los distintos modos en los que esta opera.

Sin perjuicio de lo anterior, creemos que, si bien hay importantes diferencias entre ambos, el pensamiento jurídico de Schmitt tiene como base al menos dos elementos propios de la filosofía práctica de Aristóteles: primero, que hay ciertos aspectos de la existencia (dentro de los cuales, por lo menos para Schmitt, se encuentra el derecho) donde la verdad no se determina de manera abstracta, sino que ha de tener en consideración las particularidades de la situación concreta. Segundo, que es el ser humano concreto, por medio de la consideración del contexto particular en el cual se ve en la necesidad de actuar, el único que

4 Para profundizar en las consecuencias jurídicas de la tercera crítica kantiana ver: (Wieland, 1998).

5 Kant explica que "si lo universal (la regla, el principio, la ley) es dado, la facultad de jugar, que subsume bajo él lo particular (también cuando, como facultad de juzgar trascendental da a priori las condiciones sólo conforme a las cuales se puede subsumir bajo aquel universal, es determinante" (Kant, 1992, 90). 
puede descubrir la solución justa para el caso que se sale de la regla. En palabras sencillas, el juez prudente es el único que puede hacerse caso de la excepción.

\section{Algunas conclusiones}

Comenzamos este trabajo haciendo un breve resumen de lo señalado por Herrera respecto a las similitudes que hay entre el pensamiento schmittiano y la filosofía práctica aristotélica. A continuación, argumentamos que es posible identificar otra semejanza entre las reflexiones jurídicas de Schmitt y aquellas de carácter ético del Estagirita, a saber, la importancia de la virtud de la prudencia frente a lo excepcional. En efecto, justificamos que, al señalar Schmitt que es el juez quien, a través de la decisión judicial, debe hacerse cargo de lo excepcional a la luz de lo señalado por el texto legal, está haciendo referencia a que éste ha de buscar el justo medio entre la descripción general y abstracta del texto legal, y las necesidades de justicia del caso concreto y particular ${ }^{6}$. Como bien señala Mika Ojakangas,

"por un lado, la agudeza del pensamiento de Schmitt reside en su capacidad para evitar universales y abstracciones, que no hacen referencia a una instancia concreta o al estado concreto de las cosas. Por el otro, en su aptitud para hacer distinciones conceptuales inmediatamente comprensibles, pero sin olvidar las exigencias de generalidad planteadas al pensamiento teórico.

Esta doble intención se manifiesta ya en nombre de su enfoque, combinando filosofía y vida: «Una filosofía de vida concreta»" (Ojakangas, 2006, 12).

Luego profundizamos en las similitudes del análisis que Aristóteles hace de la prudencia y el pensamiento Schmitt. Justificamos que el jurista alemán opera bajo la premisa aristotélica según la cual la justicia emana de la articulación de la generalidad y abstracción de las normas con la relatividad y contingencia de la realidad concreta. Es decir, busca una "mediación entre los polos de dicha tensión, que, al dar cuenta de su peculiar papel constitutivo, evite la tentación de reducir interpretativamente uno de ellos al otro" (Vigo, 2010, 220). En palabras sencillas, argumentamos que, por medio de la decisión judicial, Schmitt busca el justo medio entre estos dos polos, cuestión que lo lleva irremediablemente al rol que juega la prudencia en dicha mediación.

\section{Bibliografía}

Aristóteles. Ética nicomaquea, (2007), Traducido por Sinnott, Eduardo. Buenos Aires: Ediciones Colihue SRL.

Betti, E. General Theory of Interpretation, (2007), Traducido por Giorgio A. Pinton. Vol. 4. 7 vols. CreateSpace Independent Publishing Platform.

6 En ese sentido, Herrero señala que Schmitt "trata de comenzar la reflexión normativa sobre la praxis, en la praxis actual misma, y no en algún tipo de praxis ideal. Puesto que toda praxis se realiza siempre en un contexto histórico, su corrección debe valer también en él” (Herrero, 2012, LVI). 
Derrida, J. (1992), «Fuerza de ley: el "fundamento místico de la autoridad"». Doxa, n. ${ }^{\circ} 11$, pp. 129- 191.

Herrera, H. (2014), «Aristóteles y Carl Schmitt sobre el derecho natural». Kriterion: Revista de Filosofia 55, n. ${ }^{129}$, pp. 205-222.

Herrero, M. (2012), «Estudio preliminar». En Posiciones ante el derecho, de Carl Schmitt. Madrid: Editorial Tecnos.

Kant, Immanuel (1992) Crítica de la facultad de juzgar. Traducido por Pablo Oyarzún. Caracas: Monte Avila Editores.

Kaufmann, A. (2002), Filosofía del Derecho. Traducido por Luis Villar Borda y Ana María Montoya. Bogotá: Universidad del Externado de Colombia.

Kuhn, H. (1969), Der Staat: eine philosophische Darstellung. München: Kösel.

Larenz, K. (2001), Metodología de la ciencia del derecho. Traducido por M. Rodríguez Molinero. Barcelona: Ariel.

Löwith, K. (1984), «Der okkasionelle Dezisionismus von Carl Schmitt». En Sämtliche Schriften, VIII:32-71. Stuttgart: Metzler.

Ojakangas, M. (2006), A Philosophy of Concrete Life: Carl Schmitt and the Political Thought of Late Modernity. 2. ${ }^{\mathrm{a}}$ ed. Bern: Peter Lang.

Rasch, W. (2004), «Judgment: The Emergence of Legal Norms». Cultural Critique 57, n. ${ }^{\circ}$ 1, pp. 93-103.

Schmitt, C. (2012a), «Ley y juicio. Examen sobre el problema de la praxis judicial». En Posiciones ante el derecho, traducido por Montserrat Herrero. Madrid: Editorial Tecnos.

Schmitt, C. (2012b), «Sobre los tres modos de pensar la ciencia jurídica». En Posiciones ante el derecho, traducido por Montserrat Herrero. Madrid: Editorial Tecnos.

Schmitt, C. (2015), Politische Theologie. Vier Kapitel zur Lehre von der Souveränität. Zehnte Auflage. Politische Theologie, von Carl Schmitt; [1]. Berlin: Duncker \& Humblot.

Strauss, L. (1998), «Anmerkungen zu Carl Schmitt, Der Begriff des Politischen». En : : Carl Schmitt, Leo Strauss und «Der Begriff des Politischen». Zu einem Dialog unter Abwesenden, editado por Heinrich Meier. Stuttgart \& Weimar: Metzler.

Strauss, L. (1971), Natural Right and History. Chicago \& London: The University of Chicago Press.

Vigo, A. (2010), «Autorreferencia práctica y normatividad». En Practical Rationality. Scope and Structures of Human Agency, editado por A. Vigo y A. González, Vol. 1. Reason and Normativity. Hildesheiml, Zurich, New York: Olms Verlag.

Vigo, A. (2007), Aristóteles: una introducción. Santiago, Chile: Instituto de Estudios de la Sociedad.

Wieland, Wolfgang. «Kants Rechtsphilosophie der Urteilskraft». Zeitschrift für Philosophische Forschung 52, n. 1 (1998): 1-22. 